\title{
Two-stage Synthesis of Palladium (II) Oxide Nanocrystalline Powders for Gas Sensor Application
}

\author{
Alexander M Samoylov ${ }^{*}$, Liana J Gvarishvili ${ }^{1}$, Sergey A Ivkov², Dmitry I Pelipenko ${ }^{1}$ and Petre Badica ${ }^{3}$ \\ ${ }^{1}$ Department of Chemistry, Russia \\ ${ }^{2}$ Department of Physics, Russia \\ ${ }^{3}$ National Institute of Materials Physics, Romania \\ *Corresponding author: Alexander M Samoylov, Department of Chemistry, Voronezh State University, Universitetskaya Sq. 1, 394018, Voronezh, \\ Russian Federation, Russia
}

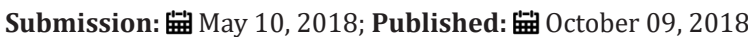

\begin{abstract}
Two-stage procedure of palladium (II) oxide nano particle powder preparation based on calcination in dry oxygen of previously synthesized palladium (II) nitrate has been developed. The results of XRD analysis testified the homogeneity of PdO samples prepared by calcination at T=400 and 600 0. By electron probe microanalysis it has been established that synthesized PdO powders were characterized with excess of oxygen atoms relative stoichiometric ratio of the elements. It has been found that calcination temperature rise from $\mathrm{T}=400 \mathrm{O} \mathrm{C}$ to $\mathrm{T}=600 \mathrm{C} \mathrm{C}$ has led to the increase of oxygen atom concentration and to enlargement of nano dimensional crystallites of palladium (II) oxide powders. Results of coherent-scattering region value determination have shown that synthesized palladium (II) oxide powders can be applied at fabrication of gas sensors within the framework of thick film technology.
\end{abstract}

\section{Introduction}

The development of industry, transport, and adoption of hightech innovations defy new environmental challenges, which were unknown before. At a turn of XX and XXI centuries most of the atmospheric ozone (90\%) was in the stratosphere with a maximum concentration between 17 and 25km [1]. However, this situation started to change during last decades. In the atmospheric air the concentration of toxic oxidizing gases with anthropogenic origin has been steadily increased over the last 20 years. Now low-level ozone and nitrogen oxides are the products of industrial and urban pollution, which has been significantly affected by motor transport and jet aircrafts. It has been established that high concentration of this powerful oxidizing gases in the ambient atmosphere is hazardous to human health [2-5]. Thus, the monitoring of ozone and nitrogen dioxide concentration in the atmosphere is a critical task for human health protection [6].

At present, several conventional analytical techniques, such as UV absorbance, optochemical, optical, chemiluminescence, fluorescence, and electrochemical methods, are available for the accurate analysis of ozone concentration in the air [7-10]. However, these methods can be realized as laboratory apparatuses only. For this reason, various types of binary, ternary and quaternary metaloxide semiconductors have widely been studied for fabrication of portable gas sensor device for individual use [1,11-15].

Recently it has been shown that palladium (II) oxide thin and ultra-thin films have encouraging prospects for application in oxidizing gas detection [16-18]. At the very initial stage of PdO thin film study the experimental data demonstrated the good sensitivity, operation speed, reproducibility, and stability in time of test results at detection of ozone and nitrogen dioxide threshold limit value (TLV) concentration [17,18]. It is known [19] the values of gas sensor functional parameters depend upon not only the size of nanoparticles but upon the shape of them also. Therefore, it is very interesting to study the gas sensor properties of palladium (II) oxide nanostructures with other morphology, for example, nanocrystalline powders or ceramics.

For this purpose, we have begun to study of the functional parameters of gas sensors based on palladium (II) oxide nano particle ceramics. The present work includes the synthesis procedure of palladium (II) oxide nanocrystalline powders and results of their chemical composition, phase structure, and morphology investigation.

\section{Experimentation}

\section{Synthesis of palladium (II) nitrate powder}

According to [20], the main pathways to obtain palladium (II) oxide powders are reactions of thermal decomposition of palladium (II) hydroxide or palladium (II) nitrate (Figure 1). Prima facie, the procedure of palladium (II) oxide preparation seems to be simple and express, if commercial palladium (II) chloride, which is produced in industrial scale, would be used as the initial reagent. 
This technique (designated as Technique I in Figure 1) can be realized by two sequences of reactions:

First sequence of reactions: The precipitation of palladium (II) hydroxide by the reaction of palladium (II) chloride aqua solution with alkali:

$$
\mathrm{PdCl}_{2}{ }^{a q}+2 \mathrm{NaOH}^{a q} \rightarrow \mathrm{Pd}(\mathrm{OH})_{2}{ }^{s o l}+2 \mathrm{NaCl}^{a q}
$$

and by further thermal decomposition of the $\mathrm{Pd}(\mathrm{OH})_{2}$ sediment:

$$
\mathrm{Pd}(\mathrm{OH})_{2}^{\text {sol }} \rightarrow \mathrm{PdO}^{\text {sol }}+\mathrm{H}_{2} \mathrm{O}^{\text {gas }}
$$

However, it is known $[21,22]$ that the presence of even a trace amount of chloride anions in metal-oxide semiconductors leads to a sharp decrease in the sensitivity of gas sensors based on these materials. The preparation of $\mathrm{Pd}(\mathrm{OH})_{2}$ according to equation (1) does not guarantee a complete absence of chloride anions in sediments. As a result of thermal decomposition of $\mathrm{Pd}(\mathrm{OH})_{2}$ containing $\mathrm{Cl}^{-}$-anions impurities the powders of $\mathrm{PdO}$ can be contaminated with chloride anions too. Palladium (II) oxide with $\mathrm{Cl}^{-}$-anions is not applicable for gas sensitive property investigation. To prevent the contamination of $\mathrm{PdO}$ with $\mathrm{Cl}^{-}$-anions the second sequence of reactions can be used.

Second sequence of reactions: In this case initial $\mathrm{PdCl}_{2}$ aqua solution reacts with silver nitrate $\mathrm{AgNO}_{3}$ to produce palladium (II) nitrate (Figure 1).

$$
\mathrm{PdCl}_{2}{ }^{a q}+2 \mathrm{AgNO}_{3}{ }^{a q} \rightarrow 2 \mathrm{AgCl}^{\mathrm{sol}}+\mathrm{Pd}\left(\mathrm{NO}_{3}\right)_{2}^{a q}
$$

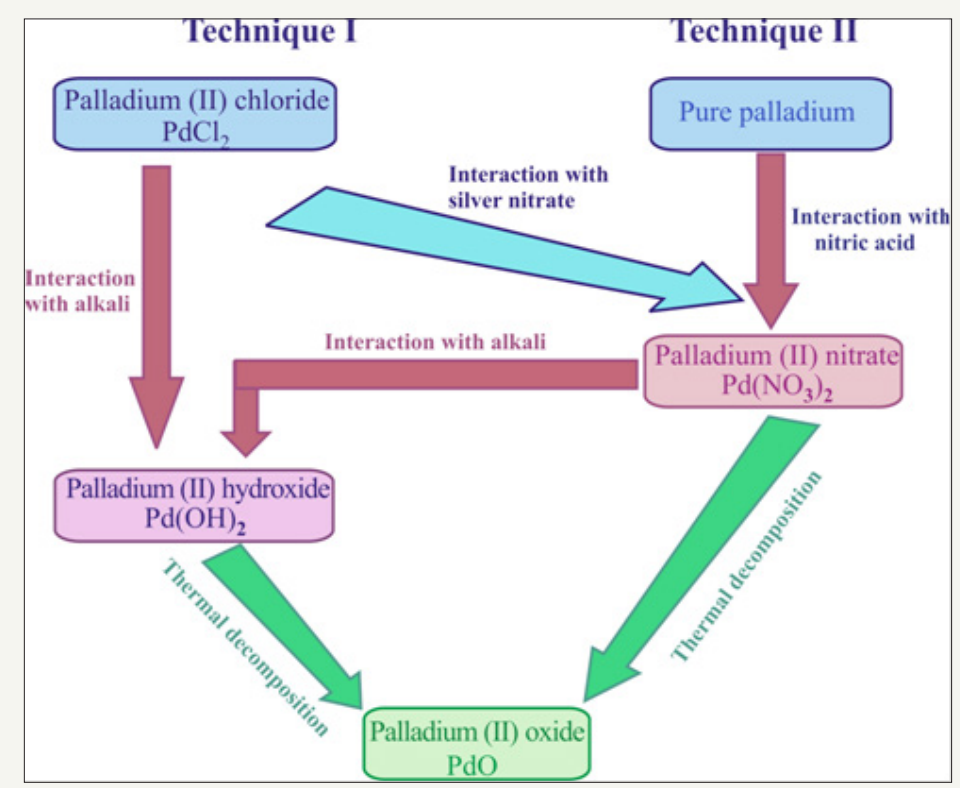

Figure 1: The possible pathways of palladium (II) oxide synthesis.

Palladium (II) oxide can be obtained by thermal decomposition of $\mathrm{Pd}\left(\mathrm{NO}_{3}\right)_{2}$ :

$$
2 \mathrm{Pd}\left(\mathrm{NO}_{3}\right)_{2}^{\text {sol }} \rightarrow 2 \mathrm{PdO}^{\text {sol }}+4 \mathrm{NO}_{2}^{\text {gas }}+\mathrm{O}_{2}^{\text {gas }}
$$

(4)This technique can provide the formation of pure palladium (II) oxide powders but using of $\mathrm{AgNO}_{3}$ makes it rather expensive.

It is known the method for preparation of palladium (II) oxide powders based on the thermal decomposition of soluble in water palladium (II) salt aerosols [21]. As carrier gas used for aerosol transport to reactor the nitrogen and ambient air have been chosen. The major task of this method was to control over PdO and, finally, Pd particle size and morphology [23]. It is necessary to note, that there are some mistakes in description of $\mathrm{PdO}$ particles preparation procedure [23]. For instance, in this technique palladium (II) sulfate $\mathrm{PdSO}_{4}$ and palladium (II) phosphate $\mathrm{Pd}_{3}\left(\mathrm{PO}_{4}\right)_{2}$, which are insoluble in water at ambient temperature, together with $\mathrm{Pd}\left(\mathrm{NO}_{3}\right)_{2}$ have been listed as soluble in water palladium (II) salts [23]. Because $\mathrm{PdSO}_{4}$ and $\mathrm{Pd}_{3}\left(\mathrm{PO}_{4}\right)_{2}$ are insoluble in water, these salts cannot be used for preparation of water aerosols.
The analysis of possible pathways for preparation of palladium (II) oxide powders lets us to suggest (Figure 1) that $\mathrm{Pd}\left(\mathrm{NO}_{3}\right)_{2}$ is the best precursor for it. In this work two-stage technique of palladium (II) oxide powders synthesis has been used (designated as Technique II in Figure 1). First stage of it is reaction of palladium with concentrated nitric acid:

$$
\mathrm{Pd}^{\mathrm{sol}}+4 \mathrm{HNO}_{3}^{a q} \rightarrow \mathrm{Pd}\left(\mathrm{NO}_{3}\right)_{2}+2 \mathrm{NO}_{2} \uparrow+2 \mathrm{H}_{2} \mathrm{O}(5)
$$

and second stage is thermal decomposition of solid $\mathrm{Pd}\left(\mathrm{NO}_{3}\right)_{2}$ according to Eq. (4).

At this technique the initial substances are palladium with 99.999 per cent purity and concentrated nitric acid prepared from commercial reagent (purity 99.98 per cent) by distillation. The distillation of concentrated $\mathrm{HNO}_{3}$ has been performed in order to eliminate $\mathrm{Cl}^{-}$-anions, which are presented as hydrochloric acid impurity in commercial reagent. The purity of distilled nitric acid has been checked by reaction with $\mathrm{AgNO}_{3}$. 
The synthesis of palladium (II) nitrate was carried out at $\mathrm{T}=75$ $80{ }^{\circ} \mathrm{C}$ in porcelain reactor during 100 hours (with interruptions). At temperature $\mathrm{T}=40-45{ }^{\circ} \mathrm{C}$ the dark brown solution has been evaporated until the formation of $\mathrm{Pd}\left(\mathrm{NO}_{3}\right)_{2}$ nano dimensional crystals. As in aqueous solution palladium (II) salts are subjected to hydrolysis, an evaporation of palladium (II) nitrate solution has been carried out at $\mathrm{pH}=4.0-4.5$ values.

\section{Synthesis of palladium (II) oxide powder}

Nanocrystalline PdO powders have been prepared by $\mathrm{Pd}\left(\mathrm{NO}_{3}\right)_{2}$ calcination in dry oxygen atmosphere at temperature $\mathrm{T}_{\text {calc }}=400{ }^{\circ} \mathrm{C}$ and $600{ }^{\circ} \mathrm{C}$. The duration of $\mathrm{Pd}\left(\mathrm{NO}_{3}\right)_{2}$ calcination procedure was 240 minutes.

\section{Analysis of palladium (II) nitrate and palladium (II) oxide}

In 2Q region of 20-120 degrees X-ray diffraction (XRD) patterns of $\mathrm{Pd}\left(\mathrm{NO}_{3}\right)_{2}$ and PdO powders were obtained with filtered CoKa 1 -radiation $(\lambda=0.179026 \mathrm{~nm})$ on a DRON-8 general purpose diffractometer (Bourevestnik, Russian Federation) with 0.02 degree step-by-step movement and sample rotation. XRD patterns were interpreted using the JCPDS database [24]. Using Scherrer equation the values of coherent-scattering region (CSR) have been calculated for palladium (II) oxide powders only because XRD data for palladium (II) nitrate were obtained in 1939 [25] and many reflexes on $\mathrm{Pd}\left(\mathrm{NO}_{3}\right)_{2}$ are not indexed until now. For calculation of PdO powders CSR average value the profiles of five more intensive reflexes with 0.01degree step-by-step movement have been recorded.

The quantitative elemental composition of powders which were prepared by palladium (II) nitrate calcination in dry oxygen, has been determined by electron probe microanalysis (EPMA) on JEOL JSM 6510 equipped with Oxford Instruments INCAX-sight energy dispersion spectrometer (EDS). The EDS analysis has been performed in five different regions of each sample.

\section{Results and Discussion}

In the present work XRD analysis was used to identify the substance formed by the interaction of metallic palladium with nitric acid. After evaporation of aqua solution, the dark brown powder was obtained. XRD patterns of this substance are presented in Table 1. By XRD study of this powder (Table 1) it has been established that interplanar distance $d_{\text {hkl }}$ values of this substance are in total compliance with JCPDS database ones for palladium (II) nitrate $\mathrm{Pd}\left(\mathrm{NO}_{3}\right)_{2}[24,25]$. Thus, we are convinced that the product of palladium and nitric acid interaction was palladium (II) nitrate.

Table 1: XRD experimental and JCPDS data [23,24] on palladium(II) nitrate crystal structure.

\begin{tabular}{|c|c|c|c|c|c|}
\hline \multirow{2}{*}{ Refelex Number } & \multirow[b]{2}{*}{ Miller Index } & \multicolumn{2}{|c|}{ JCPDS data $[23,24]$} & \multicolumn{2}{|c|}{ Experiment } \\
\hline & & $\begin{array}{l}\text { Interplanar Distance } \\
\qquad \mathbf{d}_{\mathrm{wd}} \mathbf{n m}\end{array}$ & $\begin{array}{l}\text { Intensity } \\
\text { I, arb, Units }\end{array}$ & $\begin{array}{l}\text { Interplanar Distance } \\
\mathbf{d}_{\mathrm{wd} d^{\prime}} \mathbf{n m}\end{array}$ & $\begin{array}{l}\text { Intensity } \\
\text { I, arb, Units }\end{array}$ \\
\hline 1 & --- & 0.5800 & 48 & 0.58841 & 46.2 \\
\hline 2 & --- & 0.5300 & 24 & 0.53125 & 100 \\
\hline 3 & --- & 0.4850 & 5 & 0.48322 & 8.38 \\
\hline 4 & --- & 0.4220 & 100 & 0.42357 & 21.25 \\
\hline 5 & $(200)$ & 0.3930 & 40 & 0.39419 & 44.83 \\
\hline 6 & $(210)$ & 0.3580 & 11 & --- & --- \\
\hline 7 & --- & 0.3480 & 11 & 0.34811 & 10.33 \\
\hline 8 & --- & 0.2950 & 48 & 0.29603 & 22.81 \\
\hline 9 & $(220)$ & 0.2800 & 64 & 0.28063 & 39.96 \\
\hline 10 & $(221)$ & 0.2650 & 24 & 0.26521 & 83.24 \\
\hline 11 & --- & 0.2560 & 16 & 0.25649 & 17.35 \\
\hline 12 & (311) & 0.2400 & 16 & 0.24182 & 29.82 \\
\hline 13 & $(222)$ & 0.2300 & 16 & 0.23195 & 8.77 \\
\hline 14 & --- & 0.2250 & 2 & --- & -- \\
\hline 15 & (321) & 0.2100 & 40 & 0.21062 & 9.75 \\
\hline 16 & --- & 0.2060 & 16 & 0.20773 & 13.84 \\
\hline 17 & $(400)$ & 0.1960 & 8 & --- & --- \\
\hline 18 & $(410)$ & 0.1900 & 13 & 0.19256 & 10.72 \\
\hline 19 & (331) & 0.1820 & 24 & 0.18178 & 9.75 \\
\hline 20 & --- & 0.1780 & 13 & --- & --- \\
\hline
\end{tabular}




\begin{tabular}{|c|c|c|c|c|c|}
\hline 21 & $(420)$ & 0.1740 & 24 & 0.17468 & 0.16939 \\
\hline 22 & $(332)$ & 0.1690 & 2 & -- & 7.99 \\
\hline 23 & $(431)$ & 0.1540 & 13 & --- & -- \\
\hline 24 & $(511)$ & 0.1510 & 10 & 0.14395 & 8.77 \\
\hline 25 & $(521)$ & 0.1440 & 11 & 0.1389 & 8.45 \\
\hline 26 & $(440)$ & 0.1440 & 13 & \\
\hline
\end{tabular}

By calcinations of $\mathrm{Pd}\left(\mathrm{NO}_{3}\right)_{2}$ in dry oxygen the black powders with dark green blink were prepared. EPMA results of chemical composition of these products are presented in Figure 2 and Table 2. As it can be seen in Figure 2, X-ray spectra within energy interval $\mathrm{E}=0-10 \mathrm{eV}$ are characterized with palladium and oxygen lines only. The results of quantitative chemical analysis (Table 2) have shown that the molar ratio of the elements meets to the nominal formula PdO-palladium (II) oxide. It is necessary to note that chemical composition of this oxide (Table 2) does not correspond the stoichiometric ratio 1:1 of the elements and is characterized with little excess of oxygen atoms: $\mathrm{PdO}_{1+\delta}$. The data in Table 2 have illustrated that deviation from stoichiometric ratio $\delta=0.149 \pm 0.004$ and $\mathrm{d}=0.223 \pm 0.005$ for samples prepared by calcinations at $\mathrm{T}_{\text {calc }}=400^{\circ} \mathrm{C}$ and $\mathrm{T}_{\text {calc }}=600^{\circ} \mathrm{C}$, respectively.

Table 2: EPMA results of chemical composition study of the products prepared by $\operatorname{Pd}(\mathrm{NO}) 2$ calcination at Tcolc $=400$ ${ }^{\circ} \mathrm{C}$ and $600{ }^{\circ} \mathrm{C}$

\begin{tabular}{|c|c|c|c|}
\hline \multicolumn{4}{|c|}{ Temperature of $\mathrm{Pd}\left(\mathrm{NO}_{3}\right)_{2}$ Calcination $\mathrm{T}_{\text {calc }}=400{ }^{\circ} \mathrm{C}$} \\
\hline Element & X-ray Line & Mass fraction $\omega, \%$ & Mole fraction $\mathrm{x}, \%$ \\
\hline Palaldium & L-line & 14.74 & 53.49 \\
\hline Oxygen & K-line & 85.26 & 46.51 \\
\hline Total: & & $100 \%$ & $100 \%$ \\
\hline Composition & & \multicolumn{2}{|c|}{$* \mathrm{PdO}_{1,149 \pm 0,004} / \mathrm{Pd}_{0,870 \pm 0,0004} \mathrm{O}$} \\
\hline \multicolumn{4}{|c|}{ Temperature of $\mathrm{Pd}\left(\mathrm{NO}_{3}\right)_{2}$ Calcination $\mathrm{T}_{\text {calc }}=600^{\circ} \mathrm{C}$} \\
\hline Element & X-ray Line & Mass fraction $\omega, \%$ & Mole fraction $\mathrm{x}, \%$ \\
\hline Palaldium & L-line & 15,53 & 55,01 \\
\hline Oxygen & K-line & 84,47 & 44,99 \\
\hline Total: & & $100 \%$ & $100 \%$ \\
\hline Composition & & \multicolumn{2}{|c|}{$* \mathrm{PdO}_{1,123 \pm 0,005} / \mathrm{Pd}_{0,818 \pm 0,0004} \mathrm{O}$} \\
\hline
\end{tabular}

*The statistical error for five EPMA measurements for each sample is presented
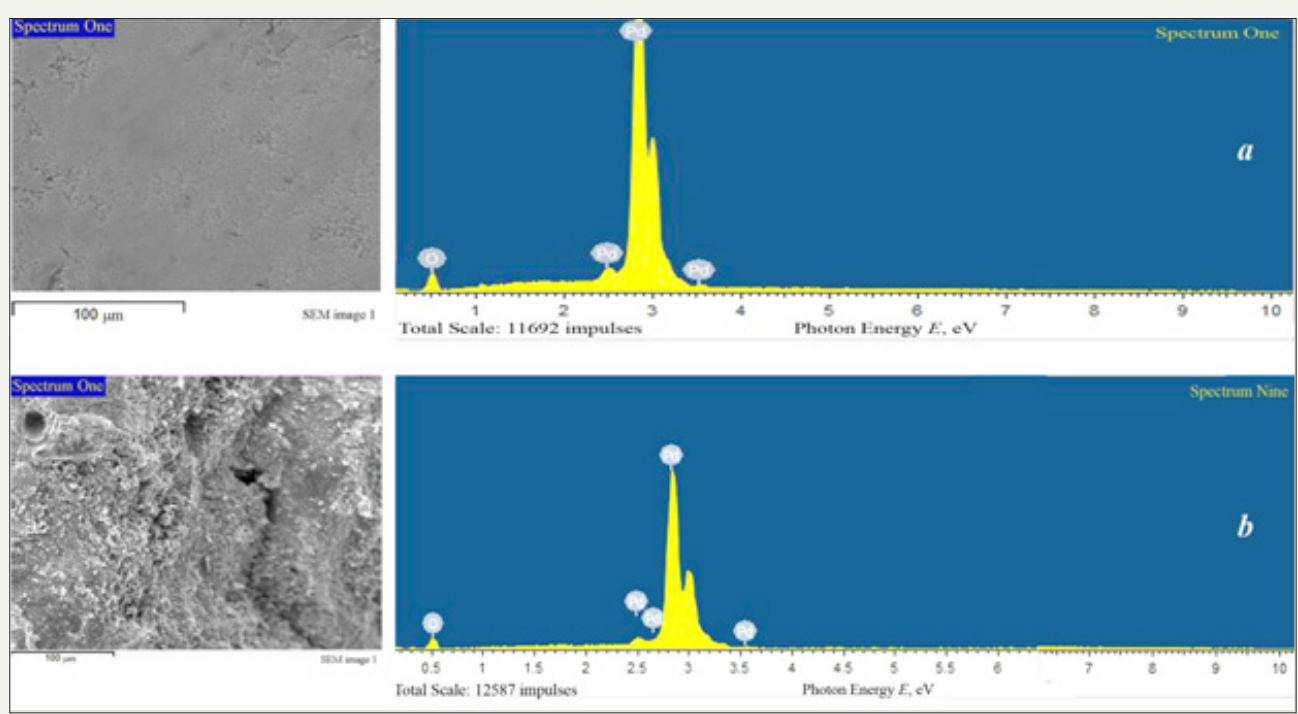

Figure 2: EPMA ED spectra and analysis region SEM micrographs of palladium (II) oxide powders prepared by calcination of palladium (II) nitrate at different temperature $\mathrm{T}_{\text {calc }}: 2 \mathrm{a}: \mathrm{T}_{\text {calc }}=400{ }^{\circ} \mathrm{C}, 2 \mathrm{~b}: \mathrm{T}_{\text {calc }}=600{ }^{\circ} \mathrm{C}$. 
It is known [26,27] that in palladium-oxygen system can be formed metastable palladium (IV) oxide $-\mathrm{PdO}_{2}$. In order to identify the phase nature of prepared palladium oxide XRD analysis has been performed. The results of XRD analysis depicted in Figure 3 have testified that all samples were homogeneous and consisted of single-phase palladium (II) oxide (tetragonal structure, space group $\mathrm{P}_{2} / \mathrm{mmc}$ ) [28]. The values of interplanar spacing $\mathrm{d}_{\mathrm{hkl}}$ are in a good agreement with ones of JCPDS database [25,28].

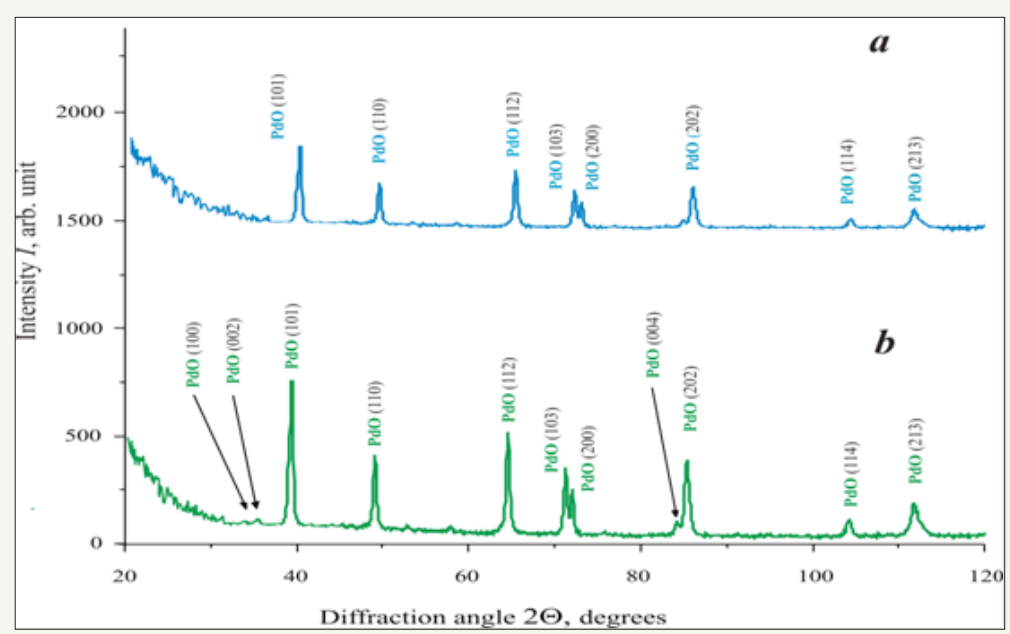

Figure 3: XRD patterns of palladium (II) oxide powders prepared by calcination of palladium (II) nitrate at different temperature $\mathrm{T}_{\text {calc: }} 3 \mathrm{a}: \mathrm{T}_{\text {calc }}=400{ }^{\circ} \mathrm{C} ; 3 \mathrm{~b}: \mathrm{T}_{\text {calc }}=600{ }^{\circ} \mathrm{C}$.

Using the special software based on solution algorithm of quadric equation's system with two unobvious parameter the values of a and $\mathrm{c}$ lattice parameters of PdO tetragonal structure have been calculated. Nelson-Riley approximation for $2 \Theta=180$ degrees diffraction angle has been performed for the refinement and more precise determination of a and c lattice parameter values.
The comparison of calculated a and c parameter values with JCPDS database standard is presented in Table 3. Analyzing the data in Table 3 it is possible to see that values of a and c lattice parameters of synthesized PdO powder samples are very close to JCPDS database ones [24,28].

Table 3: Lattice parameters a and c of PdO tetragonal crystal structure and coherent-scattering region (CSR) values calculated by Scherrer equation.

\begin{tabular}{|c|c|c|c|}
\hline \multirow{2}{*}{ PdO Sample } & \multicolumn{2}{|c|}{ Tetragonal Structure Lattice Parameter } & \multirow{2}{*}{ Coherent-Scattering Region (CSR) $\boldsymbol{\tau}, \mathbf{n m}$} \\
\cline { 2 - 3 } & $\mathbf{a}, \mathbf{n m}$ & $\mathbf{c}, \mathbf{n m}$ & $38 \pm 18$ \\
\hline $\begin{array}{c}\mathrm{PdO} \text { powder } \\
\left(\mathrm{T}_{\text {calc }}=400{ }^{\circ} \mathrm{C}\right)\end{array}$ & $0.30261 \pm 0.00006$ & $0.52567 \pm 0.00006$ & $63 \pm 15$ \\
\hline $\begin{array}{c}\mathrm{PdO} \text { powder } \\
\left(\mathrm{T}_{\text {calc }}=600^{\circ} \mathrm{C}\right)\end{array}$ & $0.30346 \pm 0.00006$ & $0.53375 \pm 0.00006$ & $\cdots$ \\
\hline JCPDS database $[24,27]$ & $0.30434 \pm 0.00004$ & $0.53375 \pm 0.00005$ & - \\
\hline
\end{tabular}

The average values of coherent-scattering region (CSR) $\tau$ of PdO powders prepared by calcinations at $\mathrm{T}_{\text {calc }}=400{ }^{\circ} \mathrm{C}$ and $\mathrm{T}_{\text {calc }}=600{ }^{\circ} \mathrm{C}$ calculated with the help of Scherrer equation are shown in Table 3. As a first approximation at $\tau$ calculation the dimensionless factor $\mathrm{K}$ was adopted equal 0.9 that is permissible for crystalline, the shape of which is close to spherical. Probably, sufficiently high values of statistical error $\Delta \tau$ are caused by two reasons. Firstly, PdO nano crystallites have various dimensions for different crystallographic directions. Secondly, the real shapes of PdO particles may differ from spherical. Nevertheless, the data obtained by EPMA and XRD experiment concerning the composition, phase structure, and crystalline sizes of palladium (II) oxide powders allow us to resume that synthesis procedure, which is set forth in this work, can provide the manufacturing of materials applicable for gas sensors fabrication within the framework of thick-film or ceramic technologies.

Comparing of XRD patterns (Figure 3) with the values of a and c lattice parameters and CSR calculation results (Table 3 ) it is possible to see the obvious tendencies. With the rise of calcination temperature $\mathrm{T}_{\text {calc }}$ the microstructure of palladium (II) oxide samples is exposed to changes in three aspects. At first, the quantity of XRD reflexes and their intensities increase. Secondly, the values of a and c lattice parameters of palladium (II) oxide tetragonal structure increase too. Thirdly, the results of CSR calculation have confirmed the enlargement of PdO nano dimensional particles. All these facts give evidence of the advancement of palladium (II) oxide structural perfection degree with the rise of calcination temperature. 
It is necessary to discuss the established tendencies of $\mathrm{PdO}$ powdermicrostructure changes together with the results of chemical composition study. It is well-known that EPMA analysis of oxygen atom concentration using ED spectrometers does not provide the absolute accuracy of experimental results. Nevertheless, from the qualitative point of view the EPMA experimental results (Table 2) are in agreement with the hypothesis, which was expressed in previous publications $[29,30]$, that palladium (II) oxide thin films and single crystals are characterized by the deficiency of palladium atoms relative stoichiometric ratio 1:1. The chemical composition formulae of palladium (II) oxide samples (Table 2) can be recalculated as: $\mathrm{PdO}_{1,149 \pm 0,004}$ or $\mathrm{Pd}_{0,870 \pm 0,004} \mathrm{O}$ and $\mathrm{PdO}_{1,223 \pm 0,005}$ or $\mathrm{Pd}_{0,818 \pm 0,004} \mathrm{O}$. Besides, it is interesting to consider the tendency of chemical composition changes with calcination temperature $\mathrm{T}_{\text {calc }}$ rise. Evidently, in PdO powder sample the deficiency of palladium atoms or, in other words, the excess of oxygen atoms increases with calcination temperature $\mathrm{T}_{\text {calc }}$ (Table 2 ).

It is necessary to emphasis that until now the nature of the point defects responsible for the nonstoichimetry of palladium (II) oxide is not established finally [30]. Palladium vacancies or oxygen interstitial atoms can be the reason of palladium (II) nonstoichimetry. The solution of this problem demands the additional investigation.

\section{Conclusion}

Two-stage procedure of palladium (II) oxide nano particle powders preparation based on calcination in dry oxygen of previously synthesized palladium (II) nitrate has been developed. The results of XRD analysis testified the homogeneity of PdO samples prepared by calcination at $\mathrm{T}=400$ and $600{ }^{\circ} \mathrm{C}$. By electron probe microanalysis it has been established that prepared $\mathrm{PdO}$ powders were characterized with excess of oxygen atoms relative stoichiometric ratio of the elements. Until now the nature of the point defects responsible for the nonstoichimetry of palladium (II) oxide is not established finally. Palladium vacancies or oxygen interstitial atoms can be the reason of palladium (II) nonstoichimetry. The solution of this problem demands the additional investigation. It has been found that calcination temperature rises from $\mathrm{T}=400{ }^{\circ} \mathrm{C}$ to $\mathrm{T}=400{ }^{\circ} \mathrm{C}$ has led to increase in oxygen atom concentration and to enlargement of nano dimensional crystallites of palladium (II) oxide powders. The data obtained by EPMA and XRD experiment concerning the phase structure and crystallite sizes of palladium (II) oxide powders give evidence that synthesis procedure, which is set forth in this work, can provide the manufacturing of materials applicable for gas sensors fabrication within the framework of thick-film or ceramic technologies.

\section{References}

1. Korotcenkov G, Brinzari V, Cho BK (2016) $\mathrm{In}_{2} \mathrm{O}_{3}$ - and $\mathrm{SnO}_{2}$ - based thin film ozone sensors: fundamentals. Journal of Sensors 3816094: 1-31.

2. World Health Organization (2003) Health aspects of air pollution with particulate matter, ozone and nitrogen dioxide. Report on a WHO Working Group. Bonn, Germany.
3. Estimating Mortality Risk Reduction and Economic Benefits from Controlling Ozone Air Pollution (2008) Report of the US National Academies of Sciences. The National Academies Press, Washington, USA.

4. Uno K, Nicholls SJ (2011) Biomarkers of inflammation and oxidative stress in atherosclerosis. Biomark Med 4(3): 361-373.

5. Rodrigo R, González J, Paoletto F (2010) The role of oxidative stress in the pathophysiology of hypertension. Hypertens Res 34(4): 431-440.

6. Darvesh AS, Carroll RT, Bishayee A, Geldenhuys WJ, Van der Schyf CJ (2011) Oxidative stress and Alzheimer's disease: dietary polyphenols as potential therapeutic agents. Expert Rev Neurother 10(5): 729-745.

7. Sauter D, Weimar U, Noetzel G, Mitrovics J, Göpel W (2000) Development of modular ozone sensor system for application in practical use. Sensors and Actuators B 69(1-2): 1-9.

8. Korotcenkov G (2013) Handbook of gas sensor materials: properties, advantages and shortcomings for applications, Springer, New York, USA, p. 464

9. Korotcenkov G, Cho BK (2012) Ozone measuring: what can limit application of $\mathrm{SnO}_{2}$ based conductometric gas sensors? Sensors and Actuators B 161(1): 28-44.

10. David M, Ibrahim MH, Idrus SM (2015) Progress in ozone sensors performance: a review. Jurnal Teknologi 73(6): 23-29.

11. Jang RW, Chun YC, Han CW, Jia YS (2015) Application of $\mathrm{Au} / \mathrm{TiO}_{2}-\mathrm{WO}_{3}$ material in visible light photoreductive ozone sensors. Thin Solid Films 574: 156-161.

12. Pauly A, Dubois M, Bruneta J, Spinelle L, Ndiaye A, et al. (2012) An innovative gas sensor system designed from a sensitive organic semiconductor downstream a nanocarbonaceous chemical filter for selective detection of $\mathrm{NO}_{2}$ in an environmental context. Part II: Interpretations of $\mathrm{O}_{3}$ /nanocarbons and $\mathrm{NO}_{2}$ /nanocarbons interactions. Sensors and Actuators B 174: 652-658.

13. Belaqziz M, Amjoud M, Gaddari A, Rhouta B, Mezzane D (2014) Enhanced room temperature ozone response of $\mathrm{SnO}_{2}$ thin film sensor Superlattices and Microstructures 71: 185-189.

14. Da Silva LF, Mastelaro VR, Catto AC, Escanhoela CA, Bernardini S, et al (2015) Ozone and nitrogen dioxide gas sensor based on a nanostructured $\mathrm{SrTi}_{085} \mathrm{Fe}_{0.15} \mathrm{O}_{3}$ thin film. Journ of Alloys and Compounds 638: 374-379.

15. Varenne C, Ndiaye A, Brunet J, Monier G, Spinelle L, et al. (2012) Comparison of InP Schottky diodes based on Au or Pd sensing electrodes for $\mathrm{NO}_{2}$ and $\mathrm{O}_{3}$ sensing. Solid-State Electronics 72: 29-37.

16. Ryabtsev SV, Shaposhnik AV, Samoylov AM, Sinelnikov AA, Soldatenko SA, et al. (2016) Thin films of palladium oxide for gas sensors. Doklady Physical Chemistry 470(2): 158-161.

17. Ryabtsev SV, Ievlev VM, Samoylov AM, Kuschev SB, Soldatenko SA (2017) Microstructure and electrical properties of palladium oxide thin films for oxidizing gases detection. Thin Solid Films 636: 751-759.

18. Ievlev VM, Ryabtsev SV, Samoylov AM, Shaposhnik AV, Kuschev SB, et al. (2018) Thin and ultrathin films of palladium oxide for oxidizing gases detection. Sensors and Actuators B 255(2): 1335-1342.

19. Yamazoe N, Shimanoe K (2008) Roles of shape and size of component crystals in semiconductor gas sensors. I response to oxygen Journ. Electrochemical Society 155(4): J85-J92.

20. Greenwood NN, Earnshaw A (1997) Chemistry of the elements ( $2^{\text {nd }}$ edn), Butterworth-Heinemann, Oxford, UK, p. 1340.

21. Marikutsa AV, Rumyantseva MN, Gaskov AM, Samoylov AM (2015) Nanocrystalline tin dioxide: Basics in relation with gas sensing phenomena. Part I. Physical and chemical properties and sensor signal formation. Inorganic Materials 51(13): 1329-1347. 
22. Marikutsa AV, Rumyantseva MN, Gaskov AM, Samoylov AM (2016) Nanocrystalline tin dioxide: Basics in relation with gas sensing phenomena. Part II. Active centers and sensor behavior. Inorganic Materials 52(13): 1311-1338.

23. Glicksman HD, Kodas TT, Lyons SW (1998) Method for making palladium and palladium oxide powders by aerosol decomposition. EP 0591881 B1, Applicant E.I. Du Pont De Nemours And Company, University of New Mexico, USA.

24. JCPDS (2015) International centre for diffraction data. JCPDS-ICDD. Newtown Square, USA.

25. Hanawalt JD, Rinn HW, Frevel LK (1938) Chemical analysis by x-ray diffraction ind. Eng Chem Anal Ed 10(9): 457-512.

26. Rogers DB, Shannon RD, Sleight AW, Gillson JL (1969) Crystal chemistry of metal dioxides with rutile-related structures. Inorganic Chemistry 8(4): 841-848.
27. Viswanathan E, Sundareswari M, Jayalakshmi DS, Manjula M (2015) Theoretical investigation on structural and electronic properties of $\mathrm{PdO}_{2}$. AIP Conference Proceedings 1665: 090047(1)-090047(3).

28. Grier D, McCarthy G (1991) ICDD Grant-in-Aid. North Dakota State University, Fargo, USA.

29. Rey E, Kamal MR, Miles RB, Royce BSH (1978) The semiconductivity and stability of palladium oxide. Journ Materials Science 13(4): 812-816

30. Samoylov AM, Ryabtsev SV, Popov VN, Badica P (2018) Palladium (II) oxide nanostructures as promising materials for gas sensors. in book: novel nanomaterials synthesis and applications. George Kyzas (Ed.), IntechOpen Publishing House, London, UK, pp. 211-229.
Creative Commons Attribution 4.0

International License

For possible submissions Click Here

\section{Submit Article}

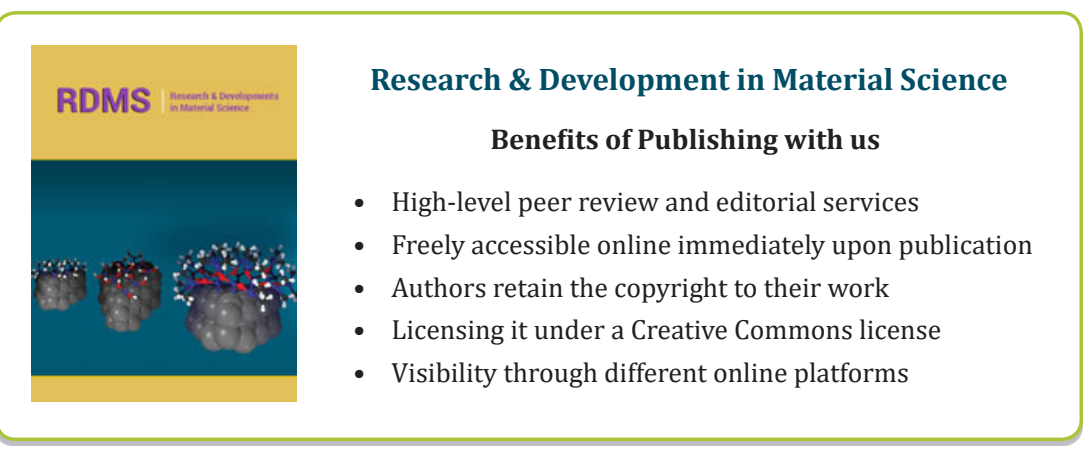

